\title{
THERMAL ANALYSIS OF AMPHIPHILIC QUATERNARY AMMONIUM CHITOSAN DERIVATIVES
}

\author{
Rafael de Oliveira Pedro, Carla C. Schmitt, Éder T. G. Cavalheiro, Miguel G. Neumann * \\ ${ }^{1}$ Instituto de Química de São Carlos, Universidade de São Paulo, Caixa Postal 970, \\ 13560-970, São Carlos SP, Brazil; \\ *neumann@iqsc.usp.br;mgneumannbr@yahoo.com.br
}

Aceito em: 10/10/2017 Publicado em: 15/12/2017

\begin{abstract}
The thermal behaviour of amphiphilic systems involving (5-pentyl)trimethylammonium and dodecyl aldehyde-modified chitosans was studied. These amphiphilic chitosan derivatives were synthesized and characterized by ${ }^{1} \mathrm{HNMR}$ and ATR-FTIR spectroscopies. Thermogravimetry (TGA) and differential scanning calorimetry (DSC) were used to determine their properties. It was found that the modification of the chitosan structure affects directly its thermal properties. The temperature at which water is released from the compounds showed that when adding the hydrophilic substituent water originally bound to an $-\mathrm{NH}_{2}$ group will bind to a less stronger $>\mathrm{NH}$ group requiring lower temperatures to be released. The addition of the hydrophobic C12 substituent confers a more micelle-like structure to the compound, leaving some water molecules within the core of the micelle, making its release more difficult. The decomposition peak observed around 300 ${ }^{\circ} \mathrm{C}$, corresponding to the decomposition of the chitosan rings, is split in two peaks when adding the substituents, indicating the influence of the substituents on the ring decomposition reactions.
\end{abstract}

Keywords: chitosan, amphiphilic derivatives, thermal stability.

\section{Introduction}

Chitin is a polysaccharide abundantly found in nature, mostly in the exoskeletons of crustaceans, molluscs and insects, and can be easily converted into chitosan by alkaline Ndeacetylation process. Chitin and chitosan are composed of 2-acetamide-2-deoxy-Dglucopyranose and 2-amino-2-deoxy-Dglucopyranose units linked by glycosidic $\beta(1 \rightarrow 4)$ bonds, in variable proportions. Chitin is predominantly composed of acetamide groups whereas chitosan has predominantly amino groups on the C-2 position of the Dglucosamine repeating unit [1]. The ratio of the $\mathrm{N}$-deacetylated units (amino) and acetylated units ( $\mathrm{N}$-acetyl) is known as degree of deacetylation (DD, \%) and significantly influences important properties of these polymers, especially chemical, physical and biological characteristics, including biocompatibility [2], biodegradability [3], antibacterial, antiviral and antifungal activity $[4,5]$. The D-glucosamine group has a $p K_{a}$ of about 6.2-7.0, therefore, in acidic conditions the amine groups will be positively charged so that chitosan will be water-soluble. This reduces uses of this polymer in neutral $\mathrm{pH}$ conditions [6].

In order to improve the properties of chitosan, both amino and hydroxyl groups present in chitosan backbone can be chemically modified in nucleophilic substitution reactions such as 
$\mathrm{N}$-alkylation, N-carboxylation [7], crosslinking [8], N-quaternization [9], N-succinylation [10] and $\mathrm{N}$-phthaloylation [11]. Increasing the positive charge density of chitosan backbone by $\mathrm{N}$-quaternization results in a higher solubility of the polymer at higher $\mathrm{pH}$ [12]. Amphiphilic derivatives can be obtained by introduction of hydrophobic and hydrophilic groups in the polymer backbone, resulting in self-assembled nanoparticles with a core-shell in aqueous solution. In this sense, amphiphilic chitosan could be used as drug delivery system, as the solubility of hydrophobic molecules is increased, as well as the drug-loading efficiency. Recent studies reported on the use of several amphiphilic chitosans as drug carriers [7,13-17].

Thermoanalytical techniques such as thermogravimetry (TGA) and differential scanning calorimetry (DSC) can be useful to monitor physical and chemical changes in both natural and grafted chitosan [18]. Modification of the chemical structure and composition of chitosan can yield specifics and reproducible patterns in the thermoanalytical curves which can be useful to understand the behaviour of the samples $[6,19,20]$, as well as to characterize them. It is possible to correlate the thermal data for the samples with those obtained by other techniques such as NMR and FTIR [21].

In this paper, an amphiphilic co-polymer was synthesized by grafting (5-bromopentyl)trimethylammonium bromide (BPTA) and dodecyl aldehyde (DDA) at different ratios to the chitosan $(\mathrm{CH})$ backbone. The thermal degradation of the amphiphilic derivatives was investigated using thermogravimetry (TGA) and differential scanning calorimetry (DSC) in order to characterize the effect of the modifications in their thermal behavior and stabilities.

\section{Materials and methods}

Materials
Chitosan powder (low molecular weight), deacetylation degree (DD) $\geq 80 \%$, 5Bromopentyl-trimethylammonium bromide (BPTA), dodecyl aldehyde (DDA), sodium hydroxide, sodium acetate, and acetic acid were used as received. All chemicals were from Sigma Aldrich Chemical Co., Germany.

Deacetylation of Chitosan.

Deacetylated chitosan was obtained via deacetylation of a commercial chitosan sample, following a known procedure [22]. Briefly, chitosan $\left(8.0 \mathrm{~g}, 4.96 \times 10^{-2}\right.$ mole of monosaccharide units) was dissolved in aqueous acetic acid solution ( $400 \mathrm{~mL}, 2 \mathrm{wt} \%)$. After complete solubilization, this solution was added drop-wise to aqueous $\mathrm{NaOH}(200 \mathrm{~mL}$, $50 \mathrm{wt} \%$ ) at room temperature and refluxed in nitrogen atmosphere at $105{ }^{\circ} \mathrm{C}$ for $1.5 \mathrm{~h}$. Afterwards it was poured in preheated water (4 L) at $60{ }^{\circ} \mathrm{C}$. The decanted precipitate was washed five times with water and separated by filtration. The solid obtained was dissolved in acetic acid solution $(200 \mathrm{~mL}, 2 \mathrm{wt} \%)$ and the procedure was repeated to achieve a higher deacetylation degree. After purification by dialysis against water for 5 days, the polymer was isolated by lyophilization (yield $7.2 \mathrm{~g}$, $90 \%$ ). The DD of the $N$-deacetylated products calculated from the integrals of the peaks of the ${ }^{1} \mathrm{H}$ NMR spectra corresponding to the three protons of the $\mathrm{N}$-acetyl group at $2.3 \mathrm{ppm}$ and the peak due to the $\mathrm{C}_{2}$ proton at $5.3 \mathrm{ppm}$ are shown in Table 1 [21].

\section{Syntheses}

PTA-modified chitosan. Grafted chitosan was prepared in aqueous $\mathrm{NaOH}$ solutions as described earlier [12]. Briefly, previously deacetylated chitosan $\left(6.0 \mathrm{~g}, 3.72 \times 10^{-2}\right.$ mole $)$ was added to $20 \mathrm{~mL}$ of $\mathrm{NaOH} 0.1 \mathrm{~mol} \mathrm{~L}^{-1}$ in a round-bottomed reaction flask equipped with a magnetic stirrer. BPTA $\left(8.0 \mathrm{~g}, 2.77 \times 10^{-2}\right.$ mole $)$ was subsequently added and stirring was continued for $72 \mathrm{~h}$ at $55^{\circ} \mathrm{C}$. The mixture was then purified by dialysis (membrane of MWCO 
$12,000 \mathrm{~g} \mathrm{~mol}^{-1}$ ) against water. Afterwards, the product was isolated by and characterized previously by ${ }^{1} \mathrm{H}$ NMR and ATR-FTIR [21].

Amphiphilic Chitosans. The syntheses of the amphiphilic chitosan derivatives were performed as previously described [21,23]. Briefly, quaternized chitosan was dissolved in acetic acid and added drop-wise to ethanol to obtain a clear solution. The $\mathrm{pH}$ of the reaction mixture was adjusted to 5.0 by adding aqueous $\mathrm{NaOH}\left(1.0 \mathrm{~mol} \mathrm{~L}^{-1}\right)$. Afterwards, dodecyl aldehyde (DDA) was added to this solution and stirred for $1 \mathrm{~h}$. Then, the solution was allowed to react for 24 hours with sodium cyanoborohydride. The product was purified by dialysis (membrane of MWCO 12,000 $\mathrm{g} \mathrm{mol}^{-1}$ ), isolated by lyophilization and characterized by ${ }^{1} \mathrm{H}-\mathrm{NMR}$, and ATR-FTIR.

\section{Characterization methods}

Thermogravimetry (TGA). The TGA curves were obtained on a thermogravimetric module SDT Q600 (TA Instruments, USA). The heating rate used was $10{ }^{\circ} \mathrm{C} \min ^{-1}$ under dynamic nitrogen atmosphere $\left(100 \mathrm{ml} \mathrm{min}^{-1}\right)$, using samples in the $2-5 \mathrm{mg}$ range and temperatures between 25 and $1000{ }^{\circ} \mathrm{C}$, in $\alpha$ alumina sample holders. TGA curves were used to verify the thermal decomposition profile of the samples. DTG curves were used to accurately determine the temperature corresponding to the release of the moisture contents, the decomposition of the organic matter and the remaining residue.

Differential Scanning Calorimetry (DSC). The differential scanning calorimetry curves (DSC) were recorded on a Q-10 module (TA Instruments, USA). These curves were taken under dynamic nitrogen atmosphere (flow 50 $\mathrm{ml} \mathrm{min}{ }^{-1}$ ) using samples of around $5.0 \pm 0.1 \mathrm{mg}$ at a heating rate of $10{ }^{\circ} \mathrm{C} \mathrm{min}-1$ under rom pressure. The modulus was calibrated for heating and temperature with metallic indium (99.9\%), according to the manufacturer's instructions.

\section{Results and discussion}

The analysed compounds (Figure 1) were deacetylated chitosan, DD $\sim 97 \%$ (II), the (pentyl)trimethylammonium bromide derivative $\left(\mathrm{CHP}_{40}\right)$ containing PTA groups (III) and the amphiphilic derivatives containing the hydrophilic group PTA (40\%) and 5 and $33 \%$ of hydrophobic dodecyl groups $\left(\mathrm{CHP}_{40} \mathrm{D}_{5}\right.$ , IV) and $\left(\mathrm{CHP}_{40} \mathrm{D}_{33}, \mathbf{V}\right)$.

Characterization of the amphiphilic derivatives

Deacetylation, quaternization and substitution degrees were calculated from the ${ }^{1} \mathrm{H}$ NMR spectra using the methods described formerly [12]. The degrees of deacetylation (DD) were calculated from the ${ }^{1} \mathrm{H}$ NMR spectra using the areas at $\delta 1.73 \mathrm{ppm}$ (corresponding to acetamidomethyl protons) and the doublet at $\delta$ $5.20 \mathrm{ppm}$ (corresponding to resonance of the anomeric proton doublet $-\mathrm{H}_{2}$ ). The degree of quaternization (DQ) of the chitosan derivative obtained by the reaction with BPTA was calculated, using the singlet at $\delta 3.41 \mathrm{ppm}$ and the signal at $\delta 1.77 \mathrm{ppm}$, which correspond to the resonance of the trimethylammonium protons of the $-\mathrm{CH}_{2} \mathrm{CH}_{2} \mathrm{CH}_{2} \mathrm{CH}_{2} \mathrm{CH}_{2} \mathrm{~N}^{+}\left(\mathbf{C H}_{3}\right)_{3}$ substituent (Fig. 1) and the resonance of the methylene protons $\mathrm{CH}_{2} \mathrm{CH}_{2} \mathrm{CH}_{2} \mathrm{CH}_{2} \mathrm{CH}_{2} \mathrm{~N}^{+}\left(\mathrm{CH}_{3}\right)_{3}$, respectively. The degree of quaternization of $\mathrm{CHP}_{40}$ could be calculated as being $42.2 \%$. The degree of substitution for the derivatives containing the dodecyl group (DDA) was calculated from areas at $\delta 1.56 \mathrm{ppm}$, attributed to resonance of the methyl protons. The DDA for $\mathrm{CHP}_{40} \mathrm{D}_{5}$ was $5.2 \%$ and for $\mathrm{CHP}_{40} \mathrm{D}_{33}$ was $33.8 \%$. The degrees of substitution of the compounds at different sites of chitosan are shown in Table 1 [21]. 
Table 1. Properties and DS (degree of substitution) of the chitosan derivatives [21].

\begin{tabular}{llll}
\hline Sample & $\mathbf{D D}^{\mathbf{a}} \mathbf{( \% )}$ & $\mathbf{D Q}^{\mathbf{b}} \mathbf{( \% )}$ & $\mathbf{D D A}^{\mathbf{c}} \mathbf{( \% )}$ \\
\hline $\mathrm{CH}$ & 96.9 & - & - \\
$\mathrm{CHP} 40$ & - & 42.2 & - \\
$\mathrm{CHP}_{40} \mathrm{D}_{5}$ & - & 42.2 & 5.2 \\
$\mathrm{CHP}_{40} \mathrm{D}_{33}$ & - & 42.2 & 33.8 \\
\hline
\end{tabular}

${ }^{\mathrm{a}}$ Deacetylation degree

${ }^{\mathrm{b}}$ Degree of hydrophilic substitution

${ }^{c}$ Degree of hydrophobic substitution
Thermal Analyses of pure chitosan and its derivatives

The TGA/DTG and DTA curves of chitosan and its derivatives in air are presented in Fig. 2. In general, all samples showed dehydration stage, followed by decomposition of the polymer and production of carbonaceous material, followed by its burning. The changes observed in the thermogravimetric profiles were attributed to the presence of the modifiers in the structures. Quantitative data are summarized in Table 2.
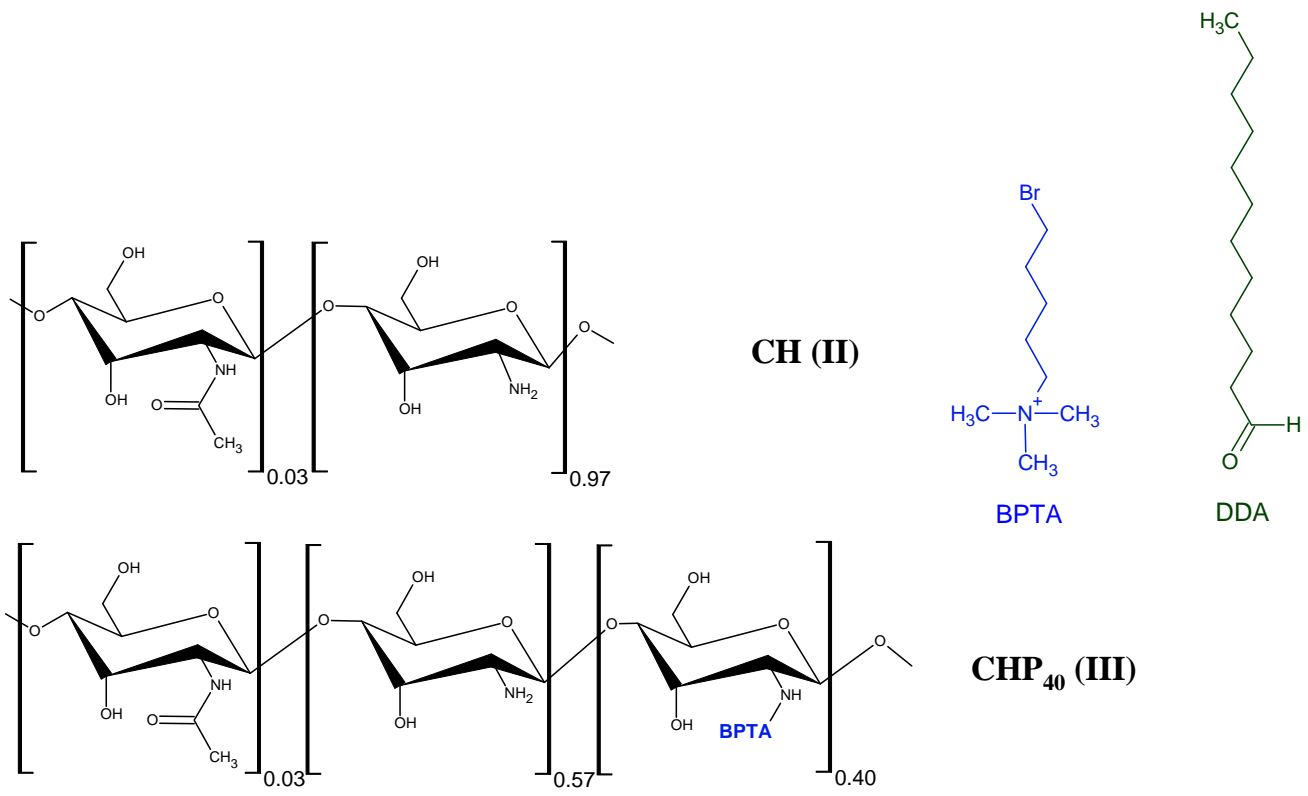

DDA

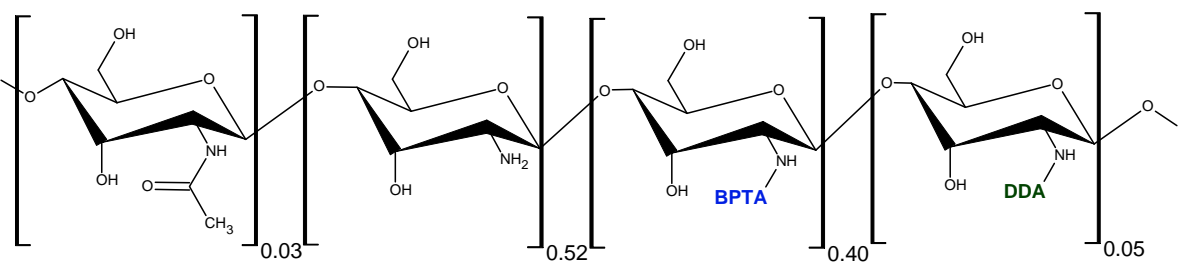

$$
\mathrm{CHP}_{40} \mathrm{D}_{5} \text { (IV) }
$$

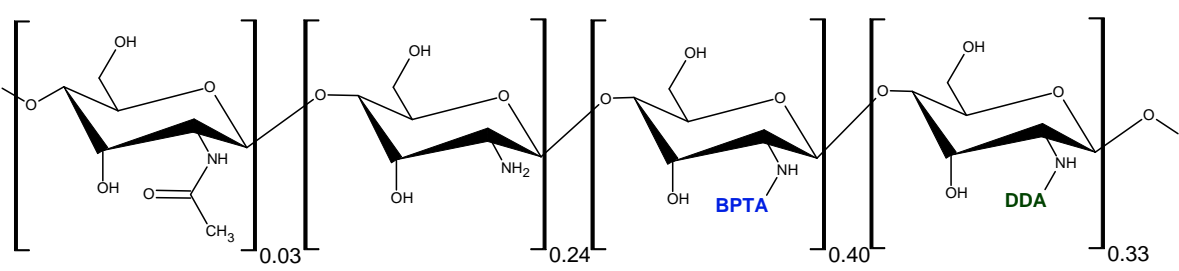

$\mathrm{CHP}_{40} \mathrm{D}_{33}(\mathrm{~V})$

Fig 1 Structural formulae of the analysed samples and compounds used in its syntheses. 
(a)

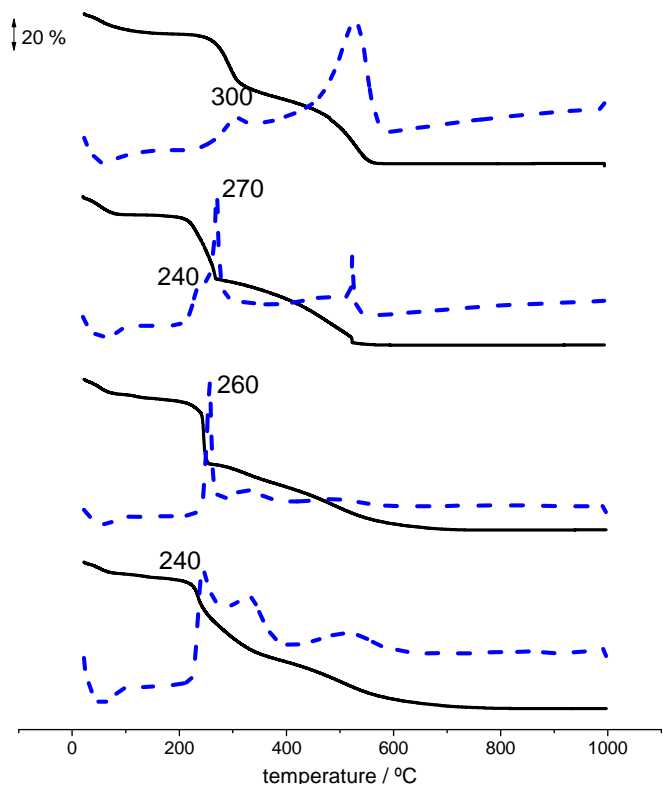

(b)

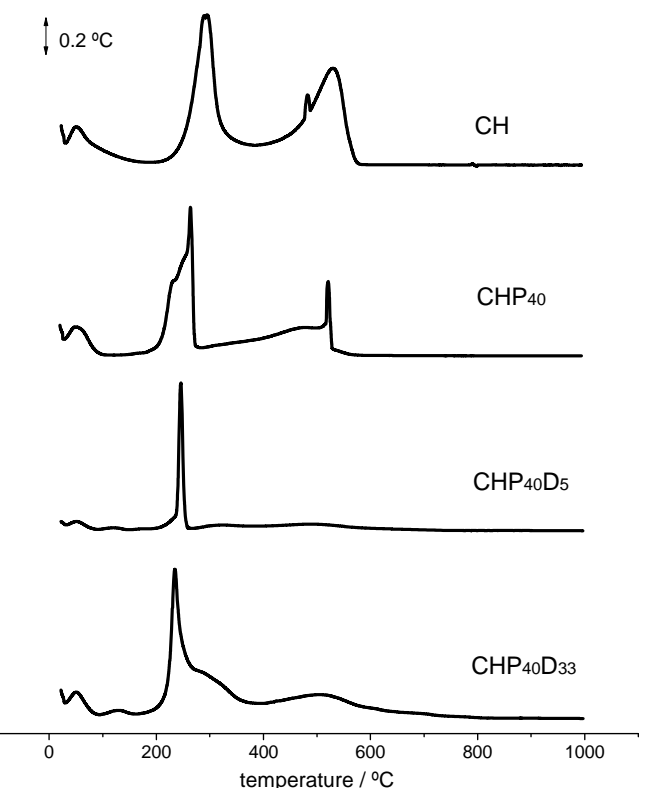

Fig. 2. (a) TGA/DTA (blue dash) and (b) DTG curves of chitosan and its derivatives. Sample mass $=2-5 \mathrm{mg}$, heating rate $=10{ }^{\circ} \mathrm{C} \mathrm{min}{ }^{-1}$, open $\alpha$-alumina sample holder.

The initial mass loss in TGA curves, up to $\sim 100^{\circ} \mathrm{C}$, indicates that the samples contain approximately $10-13 \%$ of water, involving the various types of water present in chitosan, i.e., adsorbed water and/or water weakly hydrogenbonded to the polymers [19]. The presence of the substituents decreases the weight proportion of water in the polymer, so that the total of released water will be less when adding hydrophilic and hydrophobic substituents to $\mathrm{CH}$.

The higher temperature required to release total water also increases from $\mathrm{CHP}_{40}$ to $\mathrm{CHP}_{40} \mathrm{D}_{33}$. In $\mathrm{CH}$ most of the water is $\mathrm{H}$-bonded to the $\mathrm{OH}$ and $-\mathrm{NH}_{2}$ groups. The incorporation of PTA will transform a significant amount of $\mathrm{NH}_{2}$ groups into $>\mathrm{NH}$ groups which will reduce the strength of the H-bond, and therefore require lower temperatures for the total release of the bound water. No significant effect will be sensed by the water bound to the hydroxy groups. Thus, it could reasonably be considered that most of the water linked to external quaternary ammonium groups will be easier to release.

The addition of the hydrophobic $\mathrm{C} 12$ chain will induce the formation of micelle-like structures, in which water molecules may be included, implying that the release of the bound water to internal groups will involve also a certain modification of the micellar structure, making the total release of water more difficult and requiring higher temperatures. This is consistent with the fact that for $\mathrm{CHP}_{40} \mathrm{D}_{33}$ the total release of water goes up to $166{ }^{\circ} \mathrm{C}$, whereas for $\mathrm{CHP}_{40} \mathrm{D}_{5} 153{ }^{\circ} \mathrm{C}$ is sufficient.

A decrease of $\sim 45 \%$ of the mass is observed in the range of $150-400{ }^{\circ} \mathrm{C}$ corresponding to the thermal decomposition of the polymer. The mass loss in the first thermal event for $\mathrm{CH}$, $\mathrm{CHP}_{40}, \mathrm{CHP}_{40} \mathrm{D}_{5}$ is quite similar, probably because the mol mass of the repeating units in $\mathrm{CH}$ is close to that of the modifier. However, after addition of the heavier DDA-group, the first mass loss step rises up to $55 \%$, extending it to $400^{\circ} \mathrm{C}$ (Table 2$)$. 
Table 2. DTG results for the thermal decomposition of the chitosan samples.

\begin{tabular}{l|lllllllll}
\hline Sample & $\begin{array}{l}\text { Temperature } \\
\text { Interval }\left({ }^{\circ} \mathrm{C}\right)\end{array}$ & $\begin{array}{l}\text { Weight } \\
\text { Change } \\
(\%)\end{array}$ & $\begin{array}{l}\text { Temperature } \\
\text { Interval }\left({ }^{\circ} \mathrm{C}\right)\end{array}$ & $\begin{array}{l}\text { Weight } \\
\text { Change } \\
{[1](\%)}\end{array}$ & $\begin{array}{l}\text { Temperature } \\
\text { Interval }\left({ }^{\circ} \mathrm{C}\right)\end{array}$ & $\begin{array}{l}\text { Peak } \\
\text { max }\end{array}$ & $\begin{array}{l}\text { Weight } \\
\text { Change } \\
{[2](\%)}\end{array}$ & $\begin{array}{l}\text { Residue } \\
(\%)\end{array}$ & $\begin{array}{l}\text { Ratio } \\
{[1] /[2]}\end{array}$ \\
\hline $\mathbf{C H}$ & $22-193$ & 13.3 & $193-393$ & 42.6 & $393-622$ & 300 & 43.0 & 1.6 & 0.99 \\
$\mathrm{CHP}_{40}$ & $20-136$ & 12.1 & $136-286$ & 43.3 & $286-586$ & $240+270$ & 42.1 & 2.5 & 1.03 \\
$\mathrm{CHP}_{40} \mathbf{D}_{5}$ & $22-153$ & 12.6 & $153-269$ & 44.0 & $269-737$ & $260+320$ & 42.7 & 1.2 & 1.03 \\
$\mathrm{CHP}_{40} \mathbf{D}_{33}$ & $22-166$ & 10.5 & $166-403$ & 55.4 & $403-810$ & $240+320$ & 30.3 & 3.8 & 1.83 \\
\hline
\end{tabular}

This fact reveals the influence of the substituent in the decomposition profile of the resulting polymer.

The main reaction of structure cleavage in chitosan is the formation of a radical resulting from the cleavage of the $\mathrm{C}-\mathrm{NH}_{2}$ bond. The formed radicals will induce a chain reaction leading to the splitting of the glucopyranose rings and decomposition of the polymer. This process corresponds to the peaks observed at $300,240,270$, and $240{ }^{\circ} \mathrm{C}$ for $\mathrm{CH}, \mathrm{CHP}_{40}$, $\mathrm{CHP}_{40} \mathrm{D}_{5}$, and $\mathrm{CHP}_{40} \mathrm{D}_{33}$, respectively. The onset of this step is strongly dependant on the nature of the substituent and extension of the modification performed on the structure. In general, substitution displaces this decomposition to lower temperatures, but increases for higher contents of DDA.

In addition, the bare $\mathrm{CH}$ the mass loss seems to take place as a single event. The inclusion of the hydrophilic PTA group leads to a sharp additional exothermic signal in DTA revealing a change on the decomposition mechanism when this group is present. This is corroborated by an additional sharp peak that can also be seen in the corresponding DTG curve (Fig. 2). Probably the initial fraction of the mass loss is due to the reaction in the remaining unmodified chitosan and the sharp signal corresponds to reactions of the hydrophilic PTA group or the chitosan units substituted by it. This effect of the addition of modifiers has been observed earlier by Nieto et al. $[13,24]$ for the addition of PEO to chitosan.
When the longer dodecyl chain is incorporated to the $\mathrm{CHP}_{40}$ system the mass loss observed at the beginning of the decomposition can be assigned to unsubstituted and PTA-substituted chitosan.. This decomposition is followed by a broader signal in the DTG analysis, probably representing the decomposition of the DDA containing segments, as the second signal increases as more DDA is attached to the structure, in agreement with the sharp exothermic peak in the DTA.

The DTG signals between approximately 300 and $600{ }^{\circ} \mathrm{C}$ are due to the pyrolysis of the remaining carbonaceous material resulting in vaporization and elimination of volatile products [24]. This process is similar for all the samples, although in $\mathrm{CHP}_{40}$, the process seems to occur at lower temperatures possibly due to the degradation of the residual modifier.

The ratios of mass loss 1 and mass loss 2, in Table 2 reveal that the decomposition of $\mathrm{CHP}_{40}$ and $\mathrm{CHP}_{40} \mathrm{D}_{5}$ occurs in a similar way than bare $\mathrm{CH}$ regarding the decomposition its first step followed by pyrolysis of the carbonaceous matter generated in this processes. On the other hand, the first step of decomposition and volatilization of the substituted portion of $\mathrm{CHP}_{40} \mathrm{D}_{33}$ clearly generates less carbonaceous matter, corroborating that the modifier is released in the first decomposition step, after dehydration. 
The DSC curves of derivatives are shown in Fig. 3. The curves presented a broad endothermic peak centred around $60{ }^{\circ} \mathrm{C}$, attributed to the loss of water adsorbed on the hydrophilic groups of the polymers. The different content of hydrophilic substituent on each derivative promotes shifting of the water loss peak. For example, $\mathrm{CH}$ exhibits the peak around $66{ }^{\circ} \mathrm{C}$, whereas the more hydrophilic $\mathrm{CHP}_{40}$ sample shows the peak above $70{ }^{\circ} \mathrm{C}$. This confirms that the interaction of the polymer with water depends directly on the degree of hydrophilicity. This behaviour is similar for the amphiphilic derivatives. The introduction of the hydrophobic dodecyl groups displaces the peak towards lower temperatures, $58.5^{\circ} \mathrm{C}$ for $\mathrm{CHP}_{40} \mathrm{D}_{33} 62.7{ }^{\circ} \mathrm{C}$ for $\mathrm{CHP}_{40} \mathrm{D}_{5}$, conforming that a larger amount of hydrophobic groups displaces the peak towards lower temperatures. Thus, DSC results are in agreement with those obtained by NMR [21] and TG measurements concerning the amphiphilic behaviour of the derivatives.

The unexpected peak at c.a. $75^{\circ} \mathrm{C}$ in DSC curve of the $\mathrm{CHP}_{40}$ can be related to the presence of water, or even ethanol, linked to the hydrophilic portion of the PTA modifier or even to residual free BPTA. This possibility can be correlated with the sharp mass loss observed in the DTG curve (Fig. 2b).

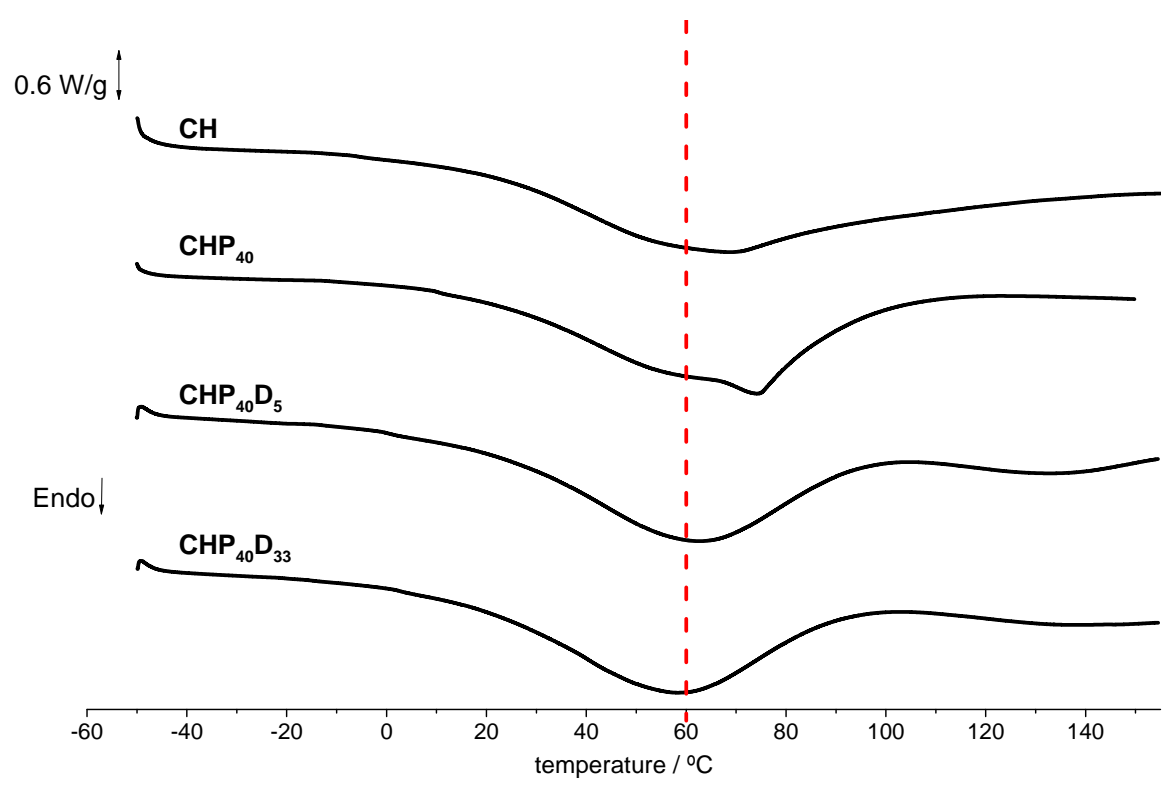

Fig. 3. DSC curves of chitosan and its derivatives. Sample mass $=5 \mathrm{mg}$, heating rate $=10{ }^{\circ} \mathrm{C} \min ^{-1}$, aluminium sample holder with a central pinhole.

\section{Conclusions}

Thermogrametry (TGA) and differential scanning calorimetry (DSC) showed that the modification of the chitosan structure affects directly its thermal properties.

The temperature at which water is released from the compounds showed that the substitution of the hydrophilic PTA substituent decreases the temperature necessary to release all the water. This effect is assigned to water originally bound to $-\mathrm{NH}_{2}$ groups is converted to water bound weaker to $>\mathrm{NH}$ groups. The addition of the hydrophobic C12 substituent confers a more micelle-like structure to the compound, leaving some water molecules 
within the core of the micelle, making its release more difficult. This effect is consisted with the previous postulation drawn from spectroscopic and imaging observations.

The decomposition peak observed around $300{ }^{\circ} \mathrm{C}$, corresponding to the decomposition of the chitosan rings, is split in two peaks when adding the substituents, indicating the influence of the substituents on the ring decomposition reactions.

From the relationship between the mass losses of the second and third peaks it can be assumed that the mechanism by which the total decomposition of bare $\mathrm{CH}, \mathrm{CHP}_{40}$, and $\mathrm{CHP}_{40} \mathrm{D}_{5}$ occur are similar, whereas for $\mathrm{CHP}_{40} \mathrm{D}_{33}$ it seems to be different. This difference may be ascribed to the micelle-like structure of this compound, as suggested in a previous report.

\section{Acknowledgements}

ROP thanks CAPES (Brazil) for a Graduate Fellowships and CCS, ETGC and MGN thank CNPq (Brazil) for a Research Fellowship. Financial support by the São Paulo Research Foundation, FAPESP (grant 2012/19656-0) is gratefully acknowledged.

\section{References}

[1] Kumar, M. (2000) A review of chitin and chitosan applications. Reactive and Functional Polymers, 46, 1-27.

[2] Du, H. L., Yang, X. Y., Pang, X., Zhai, G. $X$. (2014). The synthesis, self-assembling, and biocompatibility of a novel O-carboxymethyl chitosan cholate decorated with glycyrrhetinic acid. Carbohydrate Polymers, 111, 753-761.

[3] Kean, T., Thanou, M. (2010). Biodegradation, biodistribution and toxicity of chitosan. Advances in Drug Delivery Reviews, 62, 3-11.

[4] Rabea, E. I., Badawy, M. E. T., Stevens, C. V., Smagghe, G., Steurbaut, W. (2003). Chitosan as antimicrobial agent: Applications and mode of action. Biomacromolecules, 4, 1457-1465.

[5] Zhang H. Y., Li R. P., Liu W. (2011). Effects of chitin and its derivative chitosan on postharvest decay of fruits: A review. International Journal of Molecular Science, 12, 917-934.

[6] Zhang, A. D., Ding, D. R., Ren, J. C., Zhu, X. L., Yao, Y. H. (2014). Synthesis, characterization, and drug-release behavior of amphiphilic quaternary ammonium chitosan derivatives. Journal of Applied Polymer Science, 131, 9.

[7] Petit, C., Reynaud, S., Desbrieres, J. (2015). Amphiphilic derivatives of chitosan using microwave irradiation. Toward an eco-friendly process to chitosan derivatives. Carbohydrate Polymers, 116, 26-33.

[8] Huang, C. H., Hsieh, T. H., Chiu, W. Y. (2015). Evaluation of thermally crosslinkable chitosan-based nanofibrous mats for the removal of metal ions. Carbohydrate Polymers, 116, 249-254.

[9] Martins, A. F., Facchi, S. P., Follmann, H. D. M., Pereira, A. G. B., Rubira, A. F., Muniz, E. C. (2014). Antimicrobial activity of chitosan derivatives containing $\mathrm{N}$-quaternized moieties in its backbone: A review. International Journal of Molecular Science, 15, 2080020832.

[10] Wakita, M. A. (2013). Removal of lipopolysaccharide from protein solution using nanostructured porous supports bearing lipid membranes. Nanoscale Research Letters, 8, 7.

[11] Kurita, K. (1998). Chemistry and application of chitin and chitosan. Polymer Degradation and Stability, 59, 117-120.

[12] Pedro, R. O., Takaki, M., Goraye, T. C. C., Del Bianchi, V. L., Thomeo, J. C., Tiera, M. J., Tiera, V. A. D. (2013). Synthesis, characterization and antifungal activity of quaternary derivatives of chitosan on Aspergillus flavus. Microbiology Research, $168,50-55$. 
[13] Di Martino, A., Sedlarik, V. (2014). Amphiphilic chitosan-grafted-functionalized polylactic acid based nanoparticles as a delivery system for doxorubicin and temozolomide co-therapy. International Journal of Pharmaceutics , 474, 134-145.

[14] Ho, K. M., Li, W. Y., Wong, C. H., Li, P. (2010). Amphiphilic polymeric particles with core-shell nanostructures, emulsion-based syntheses and potential applications. Colloid and Polymer Science, 288, 1503-1523.

[15] Layek, B., Haldar, M. K., Sharma, G., Lipp, L., Mallik, S., Singh, J. (2014). Hexanoic acid and polyethylene glycol double grafted amphiphilic chitosan for enhanced gene delivery, Influence of hydrophobic and hydrophilic substitution degree. Molecular Pharmaceutics, 11, 982-994.

[16] Lu, H. W., He, H., Zhang, B., Liu, G. Q., Li, M. Y., Nie, Q. L. (2013). Facile synthesis of amphiphilic chitosan-g-poly(lactic acid) derivatives and the study of their controlled drug release. Journal of Applied Polymer Science, 130, 908-915.

[17] Park, K., Kim, J. H., Nam, Y. S., Lee, S., Nam, H. Y., Kim, K., Park, J. H., Kim, I. S., Choi, K., Kim, S. Y., Kwon, I. C. (2007). Effect of polymer molecular weight on the tumor targeting characteristics of self-assembled glycol chitosan nanoparticles. Journal of Controlled Release, 122, 305-314.

[18] Neto, C. G. T., Giacometti, J. A., Job, A. E., Ferreira, F. C., Fonseca, J. L. C., Pereira, M. R. (2005). Thermal analysis of chitosan based networks. Carbohydrate Polymers, 62, 97-103.

[19] Zawadzki, J., Kaczmarek, H. (2010). Thermal treatment of chitosan in various conditions. Carbohydrate Polymers, 80, 394400.

[20] Pawlak, A., Mucha, A. (2003). Thermogravimetric and FTIR studies of chitosan blends. Thermochimica Acta, 396, 153-166.

[21] Pedro, R. O., Schmitt, C. C., Neumann, M. G. (2016). Syntheses and characterization of amphiphilic quaternary ammonium chitosan derivatives. Carbohydrate Polymers, 147, 97103.

[22] Tiera, M. J., Qiu, X. P., Bechaouch, S., Shi, Q., Fernandes, J. C., Winnik, F. M. (2006). Synthesis and characterization of phosphorylcholine-substituted chitosans soluble in physiological $\mathrm{pH}$ conditions. Biomacromolecules, 7, 3151-3156.

[23] Souza, R. V., Takaki, M., Pedro, R. O., Gabriel, J. S, Tiera, M. J., Tiera, V. O. (2013). Hydrophobic effect of amphiphilic derivatives of chitosan on the antifungal activity against Aspergillus flavus and Aspergillus parasiticus. Molecules, 18, 4437-4450.

[24] Nieto, J. M., Peniche-Covas, C., Padrón, G. (1991). Characterization of chitosan by pyrolysis-mass spectrometry, thermal analysis and differential scanning calorimetry. Thermochimica Acta, 176, 63-68. 